\title{
INFLUÊNCIA DA GRANULOMETRIA DOS SÓLIDOS TRITURADOS DE SABUGO DE MILHO E BAGAÇO DE CANA-DE-AÇÚCAR COMO MATERIAIS FILTRANTES NO TRATAMENTO DE ÁGUAS RESIDUÁRIAS DA SUINOCULTURA
}

\section{PAOLA A. V. LO MONACO ${ }^{1}$, ANTONIO T. DE MATOS ${ }^{2}$, VIVIANE DOS S. BRANDÃO ${ }^{3}$}

RESUMO: Teve-se o objetivo de avaliar a influência da granulometria de sólidos triturados do sabugo de milho e do bagaço de cana-de-açúcar, utilizados como materiais filtrantes, na eficiência de remoção de poluentes da água residuária da suinocultura (ARS). Utilizaram-se colunas de filtragem contendo o material em três faixas granulométricas $(0,84$ a 1,19; 1,19 a 2,00 e 2,00 a $2,83 \mathrm{~mm}$ ). Para a avaliação da eficiência do sistema, o afluente e o efluente foram caracterizados em relação às seguintes variáveis: demanda bioquímica de oxigênio $\left(\mathrm{DBO}_{5}\right)$, demanda química de oxigênio (DQO), sólidos totais (ST), nitrogênio total (N-total), fósforo total (P-total), potássio (K), sódio $(\mathrm{Na})$, cobre total ( $\mathrm{Cu}$-total) e zinco total ( $\mathrm{Zn}$-total). Geraram-se curvas, relacionando-se as concentrações relativas das variáveis e a lâmina de ARS filtrada. As menores concentrações de DBO nos efluentes foram obtidas, no geral, nos filtros constituídos por materiais na sua maior granulometria; as remoções de DQO, ST, N-total e P-total não foram sensivelmente influenciadas pela granulometria dos materiais filtrantes; o K e o Na não foram retidos nos materiais filtrantes, em nenhuma das granulometrias estudadas, entretanto as remoções de $\mathrm{Zn}$-total e o $\mathrm{Cu}$-total foram, em geral, maiores nos filtros constituídos de materiais filtrantes de menor granulometria.

PALAVRAS-CHAVE: filtros orgânicos, tratamento de água, tamanho da partícula.

\section{INFLUENCE OF THE SIZE OF GROUND CORNCOB AND SUGARCANE BAGASSE AS FILTERING MATERIALS IN SWINE WASTEWATER TREATMENT}

\begin{abstract}
The objective was to evaluate the influence of particle size of the solid ground corncob and sugarcane bagasse, used as filter materials, the efficiency of removing pollutants from swine wastewater (SWW). It was used columns containing the filtering material in three particle sizes $(0.84$ to $1.19 ; 1.19$ to 2.00 and 2.00 to $2.83 \mathrm{~mm})$. To evaluate the efficiency of the system, the influent and effluent were characterized in relation to the following parameters: biochemical oxygen demand $\left(\mathrm{BOD}_{5}\right)$, chemical oxygen demand (COD), total solids (TS), total nitrogen (total-N) total phosphorus (total-P), potassium (K), sodium (Na), total copper (total-Cu) and total zinc (total- $\mathrm{Zn}$ ). Curves were generated by relating the relative concentrations of the variables and the depth of the filtered SWW. The lowest concentrations of BOD in the effluent were obtained, in general, filters made of materials in its largest size; the removals of COD, TS, total-N, total-P were not significantly influenced by the size of the filter materials; the $\mathrm{Na}$ and the $\mathrm{K}$ had not been retained in the filter materials, in none of the grain sizes studied, however the removal of total- $\mathrm{Zn}$ and total-Cu were generally higher in filters consist of filter materials of smaller particle size.
\end{abstract}

KEYWORDS: organic filter, water treatment, particle size.

\footnotetext{
${ }^{1}$ Professora, IFET do Espírito Santo, Santa Teresa - ES. paolalomonaco2004@yahoo.com.br.

${ }^{2}$ Professor Associado, Departamento de Engenharia Agrícola, Universidade Federal de Viçosa - MG, atmatos@ufv.br.

${ }^{3}$ Especialista, Superintendência de Planejamento de Recursos Hídricos da Agência Nacional de Águas - ANA vbrandao@ana.gov.br. Recebido pelo Conselho Editorial em: 19-2-2010

Aprovado pelo Conselho Editorial em: 8-6-2011
} 


\section{INTRODUÇÃO}

A suinocultura moderna, caracterizada pelo confinamento de animais, gera grandes volumes de águas residuárias, com alto poder poluente. De acordo com MATOS (2008), quando essas águas residuárias são dispostas no meio ambiente sem tratamento, podem causar grandes problemas ambientais, tais como degradação ou destruição da flora e da fauna, além de comprometer a qualidade da água e do solo.

A utilização de águas residuárias na agricultura é uma alternativa para o controle da poluição das águas superficiais e subterrâneas, disponibilização de água e fertilizantes para as culturas, reciclagem de nutrientes e aumento na produção agrícola. Entretanto, para que isso possa tornar-se uma prática viável, é preciso que sejam desenvolvidas técnicas de minimização, tratamento e destino final dos resíduos gerados (MATOS, 2008; DAL BOSCO et al., 2008).

Pesquisas têm sido desenvolvidas com o intuito de se aplicar águas residuárias na fertirrigação de culturas agrícolas (LO MONACO et al., 2007; LO MONACO et al., 2009a), o que demanda o uso de sistemas de aplicação localizada, como sendo uma forma técnica e ambientalmente adequada na disposição dessas águas. Entretanto, quando se aplicam águas residuárias ricas em material orgânico, utilizando-se de sistemas de aplicação localizada, os gotejadores ficam passíveis de entupimento frequente (BATISTA et al., 2005; BATISTA et al., 2007). Neste caso, o entupimento dos gotejadores reduz a vazão e, consequentemente, diminui a uniformidade de aplicação de água residuária. Dessa forma, torna-se necessária a execução de um tratamento preliminar e primário, para que sejam diminuídos os riscos de entupimento dos emissores.

Dentre as formas de tratamento primário para a remoção de poluentes, está a filtração, que se baseia no princípio de que um meio poroso pode reter impurezas de dimensões até menores que as dos poros da camada filtrante (BRANDÃO et al., 2003).

O uso de material filtrante alternativo, oriundo de atividades agropecuárias, pode ser boa alternativa, devido à abundância, baixo custo de aquisição e, ainda, em razão da possibilidade de ser submetido à compostagem após sua utilização como material filtrante (MATOS, 2008), tal como foi observado em trabalhos realizados por MAGALHÃES et al. (2006a), podendo ser , posteriormente, utilizado como fertilizante agrícola. Por essa razão, alguns resíduos utilizados como filtros orgânicos têm sido pesquisados, dentre eles o triturado de bagaço de cana-de-açúcar (BRANDÃO et al., 2000 e 2003; LO MONACO et al., 2002; MAGALHÃES et al., 2005; MAGALHÃES et al., 2006b); serragem de madeira (BRANDÃO et al., 2000 e 2003; LO MONACO et al., 2002; LO MONACO et al., 2004a; MAGALHÃES et al., 2005; MAGALHÃES et al., 2006b), casca de arroz (BRANDÃO et al., 2000 e 2003), triturado de sabugo de milho ( BRANDÃO et al., 2000 e 2003;), fino de carvão (BRANDÃO et al., 2000 e 2003), casca de frutos do cafeeiro (BRANDÃO et al., 2000 e 2003), fibra de coco (LO MONACO et al., 2009b), além de pergaminho de grãos de café (LO MONACO et al., 2004b; MATOS et al., 2006).

O uso de filtros orgânicos tem sido recomendado para que se promova redução na concentração de sólidos em suspensão nas águas residuárias da suinocultura, ARS (BRANDÃO et al., 2000 e 2003; LO MONACO et al., 2002; FREITAS, 2006; MAGALHÃES et al., 2005 e 2006b; LO MONACO et al., 2009b) e da separação hidráulica, e do descascamento de frutos do cafeeiro (LO MONACO et al., 2002; LO MONACO et al., 2004b; MATOS et al., 2006), para que, então, possam ser utilizados sistemas de aplicação localizada.

De acordo com LO MONACO et al. (2009), quando o meio filtrante apresentar poros de pequeno diâmetro, as partículas de maior diâmetro existentes na água residuária tendem a ser retidas nas camadas mais superficiais dos filtros, proporcionando rápido aumento na perda de carga e pequeno período de operação do filtro, porém materiais filtrantes mais finos deverão proporcionar a produção de efluentes mais depurados.

LO MONACO et al. (2004a), ao testarem três faixas granulométricas da serragem de madeira como material filtrante no tratamento da ARS, concluíram que a maior granulometria $(2,00$ a 
$2,83 \mathrm{~mm}$ ) foi a recomendada por ter sido mais eficiente na remoção de DBO, DQO e ST, e somente a partir das maiores lâminas filtradas é que a menor granulometria mostrou maior eficiência na remoção de nitrogênio (N-total). Além disso, não observaram nenhuma influência da granulometria na remoção de fósforo, sódio e potássio.

Em razão da necessidade de se obter mais informações acerca da melhor faixa granulométrica para outros materiais orgânicos, neste trabalho, teve-se como objetivo avaliar a influência da granulometria de sólidos triturados do sabugo de milho e do bagaço de cana-de-açúcar como materiais filtrantes, na eficiência de tratamento primário de águas residuárias da suinocultura.

\section{MATERIAL E MÉTODOS}

O experimento foi realizado na área experimental de Irrigação e Drenagem do Departamento de Engenharia Agrícola (DEA) da Universidade Federal de Viçosa (UFV). A água residuária utilizada (ARS) foi proveniente da Suinocultura da UFV. As colunas de filtragem foram montadas em tubos de PVC de $100 \mathrm{~mm}$ de diâmetro e $600 \mathrm{~mm}$ de comprimento. Como materiais filtrantes, foram empregados o sabugo de milho e o bagaço de cana-de-açúcar, previamente triturados em picadeira e peneirados, de modo a se obter três faixas granulométricas: pequena $(\mathrm{P})$, entre $0,84 \mathrm{e}$ 1,19; média (M), entre 1,19 e 2,00, e grande (G), entre 2,00 e 2,83 mm. Como foram realizadas três repetições para cada faixa granulométrica, foram confeccionadas 9 colunas de filtragem para cada material filtrante.

Os materiais triturados foram acondicionados nas colunas de forma gradual, em camadas de 5 $\mathrm{cm}$ de espessura, sob compressão de $12.490 \mathrm{~N} \mathrm{~m}^{-2}$ (pressão semelhante à possível de ser exercida no pisoteio do material por uma pessoa de $70 \mathrm{~kg}$ ), até ser atingida a altura de $50 \mathrm{~cm}$.

Para armazenar a ARS coletada, utilizaram-se galões de $50 \mathrm{~L}$, que permaneceram em uma bancada de onde era distribuída para os diferentes filtros posicionados em uma bancada mais baixa (Figura 1).

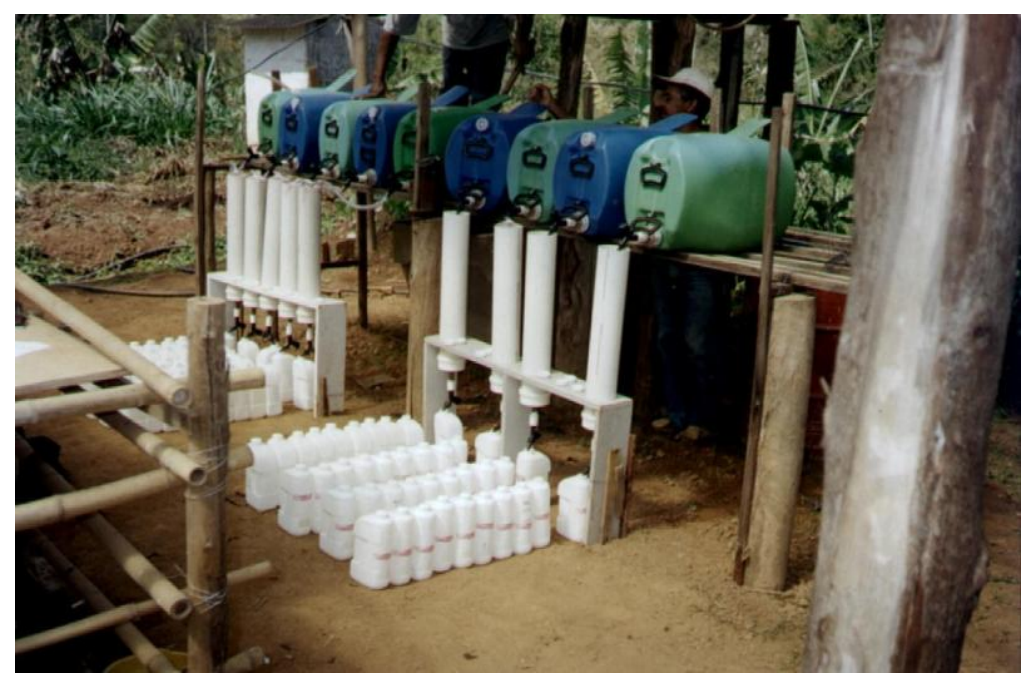

FIGURA 1. Detalhe da estrutura da bancada utilizada nos ensaios de filtração. Details of the structure of the bench used in filtration tests.

Frascos plásticos de 1,5 L foram utilizados para coleta parcelada de afluente e efluente, tendo sido acumulado um volume total de aproximadamente $10,5 \mathrm{~L}$ de efluente em cada coluna de filtragem. O escoamento foi mantido na condição permanente, em meio saturado, durante toda a fase de filtragem da ARS. Conhecendo-se o tempo para preencher o volume coletado (1,5 L), foi possível determinar a taxa de filtração da água residuária no filtro.

As análises do afluente e efluente dos filtros foram realizadas no Laboratório de Qualidade da Água do Departamento de Engenharia Agrícola da UFV, conforme recomendações contidas no 
Standard Methods for the Examination of Water and Wastewater (APHA, 2005). As variáveis avaliadas, os métodos e os equipamentos utilizados nas análises laboratoriais estão descritos a seguir: $\mathrm{DBO}_{5}, 20^{\circ} \mathrm{C}$ - obtida pela quantificação do oxigênio dissolvido pelo método iodométrico (processo Winkler); DQO - quantificada pelo método de oxidação química em refluxo aberto; Sólidos totais - quantificados pelo método gravimétrico; Sólidos Sedimentáveis - quantificados em cone Imhoff; Nitrogênio total - quantificação pelo processo semimicro Kjeldahl; Fósforo total análise realizada por meio de digestão nítrico-perclórica da amostra e quantificada em espectrofotômetro; Sódio e potássio - quantificação em fotômetro de chama, após digestão nítricoperclórica da amostra, e Cobre e zinco - quantificação em espectrofotômetro de absorção atômica, após digestão nítrico-perclórica da amostra.

O volume de efluente coletado durante a condução dos ensaios foi convertido em lâmina filtrada, sendo esta obtida pela relação entre o volume filtrado $\left(\mathrm{cm}^{3}\right)$ e a área transversal do filtro $\left(\mathrm{cm}^{2}\right)$. Desta forma, foi possível a construção de curvas relacionando-se as concentrações relativas (concentração efluente dividida pela concentração afluente) de $\mathrm{DBO}_{5}$, DQO, ST, N-total, P-total, Ktotal, Na-total, Cu-total e Zn-total, em função da lâmina filtrada.

Análises de regressão foram utilizadas para obtenção de equações que possibilitassem a estimativa do desempenho de filtragem na remoção das diversas variáveis da água residuária, tendo-se como variável independente a lâmina filtrada. Os modelos foram escolhidos com base na significância dos coeficientes de regressão, utilizando-se do teste " $t$ ", e adotando-se o nível de até $10 \%$ de probabilidade, no coeficiente de determinação $\left(\mathrm{R}^{2}\right)$ e no fenômeno em estudo.

\section{RESULTADOS E DISCUSSÃO}

Nas Figuras 2 e 3, estão representadas, respectivamente, as curvas dos efluentes coletados em filtros constituídos pelo triturado de sabugo de milho e pelo triturado de bagaço de cana-de-açúcar, nas três faixas granulométricas (P, M e G), tomando-se o eixo das abscissas como lâmina filtrada, e as ordenadas, como concentração relativa de DBO, DQO, ST, N-total, P-total, K-total, Na-total, Zntotal e $\mathrm{Cu}$-total. Como a concentração relativa $(\mathrm{C} / \mathrm{Co})$ expressa a relação entre as concentrações de saída (efluente) e de entrada no filtro (afluente), um valor de C/Co maior que 1 significa que o efluente apresenta concentração da variável em referência maior que a do afluente.

De acordo com os dados apresentados nas Figuras $2 \mathrm{~A}$ e $3 \mathrm{~A}$, os filtros mostraram-se relativamente eficientes na remoção de DBO da ARS afluente, uma vez que proporcionaram, a partir da lâmina filtrada de $100 \mathrm{~cm}$, remoções de 25 e $60 \%$ nos filtros constituídos por triturado de bagaço de cana-de-açúcar e de 50 e $40 \%$ nos filtros constituídos por triturado de sabugo de milho, para as faixas granulométricas $\mathrm{P}$ e $\mathrm{M}$, respectivamente.

As elevadas concentrações relativas $\left(\mathrm{C} / \mathrm{C}_{0}>1\right)$ de $\mathrm{DBO}$, obtidas nas primeiras lâminas filtradas dos efluentes dos filtros de sabugo de milho e bagaço de cana, evidenciam que a ARS foi capaz de solubilizar e transportar grande quantidade de sólidos e solutos que podem ser oxidados por microrganismos. Com a trituração de ambos os materiais, ocorreu aumento na superfície específica deles e, desta forma, a solubilização e transporte de componentes orgânicos desses materiais. Por essa razão, com aplicação de ARS afluente, houve grande acréscimo inicial nos valores de DBO do efluente das colunas; com o passar do tempo de operação dos filtros, a quantidade desses materiais transportados foi esgotando-se e a DBO efluente estabilizou-se. Este fato também foi observado por LO MONACO et al. (2002), trabalhando com serragem de madeira e triturado de bagaço de canade-açúcar, na faixa granulométrica de 2,83 a 4,00 mm, no tratamento da água residuária do processamento dos frutos do cafeeiro (ARC), e LO MONACO et al. (2004a), utilizando a serragem de madeira, na faixa granulométrica de 2,00 a 2,83 mm, no tratamento da ARS. 

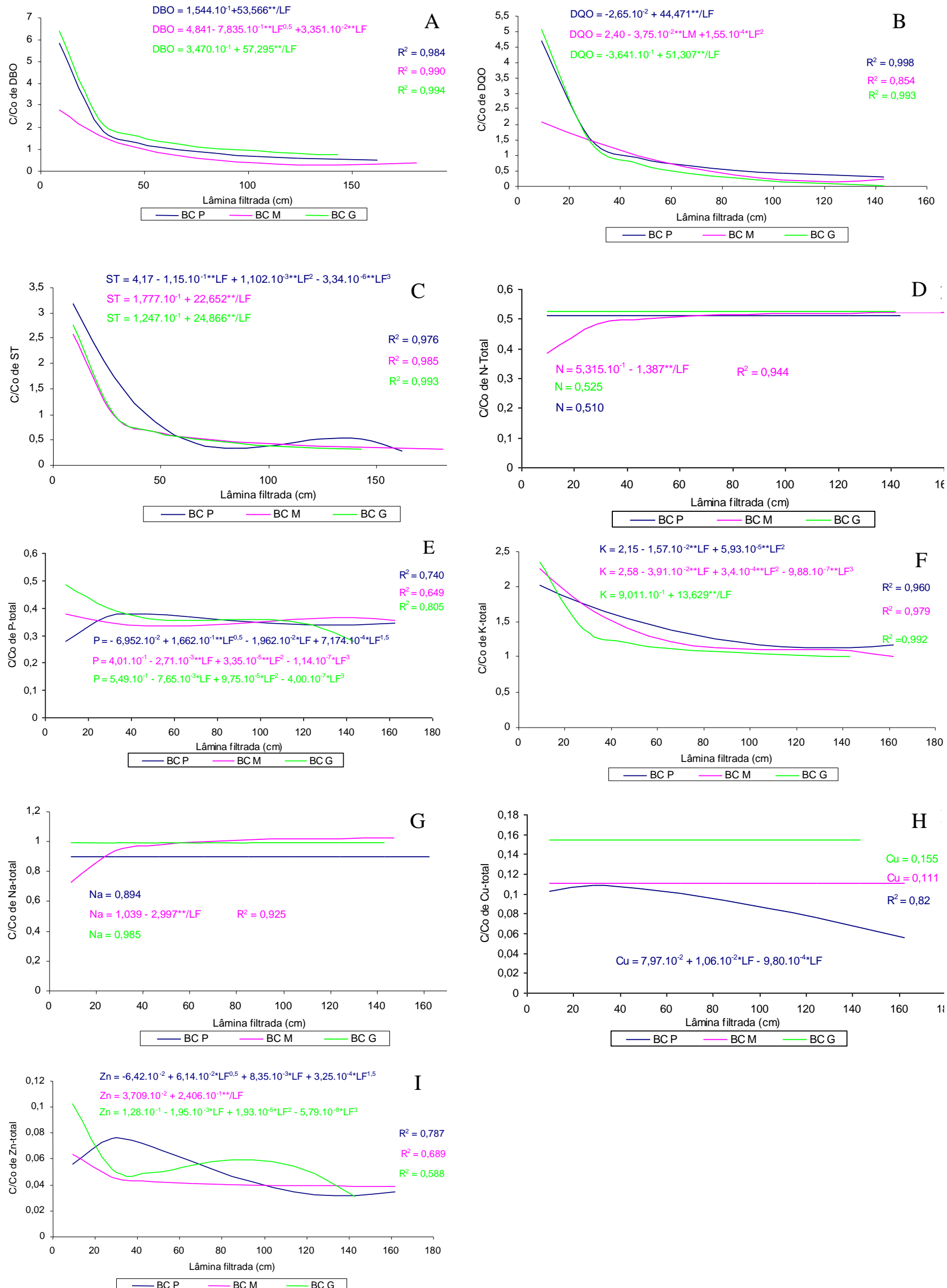

FIGURA 2. Concentração relativa estimada de (A) DBO, (B) DQO, (C) ST, (D) N-total, (E) P-total, (F) K, (G) Na, (H) Cu-total e (I) Zn-total no efluente dos filtros que receberam água residuária da suinocultura em função da lâmina filtrada, em filtros compostos de triturado de bagaço de cana-de-açúcar, em três faixas granulométricas: P - pequeno $(0,84$ a $1,19 \mathrm{~mm})$, M-médio $(1,19$ a $2,00 \mathrm{~mm})$ e G - grande $(2,00$ a 2,83 mm). Estimated relative concentration of (A) BOD, (B) COD, (C) TS, (D) total-N, (E) total-P (F) K, (G) Na, (H) total-Cu and (I) total-Zn in the effluent of the filters receiving swine wastewater as a function of blade filtered in filters composed of sugar-cane fiber in three particle sizes: $\mathrm{S}$ - small $(0.84$ to $1.19 \mathrm{~mm})$, M-medium $(1.19$ to $2.00 \mathrm{~mm})$ and $\mathrm{G}$ - large $(2.00$ to $2.83 \mathrm{~mm})$. 

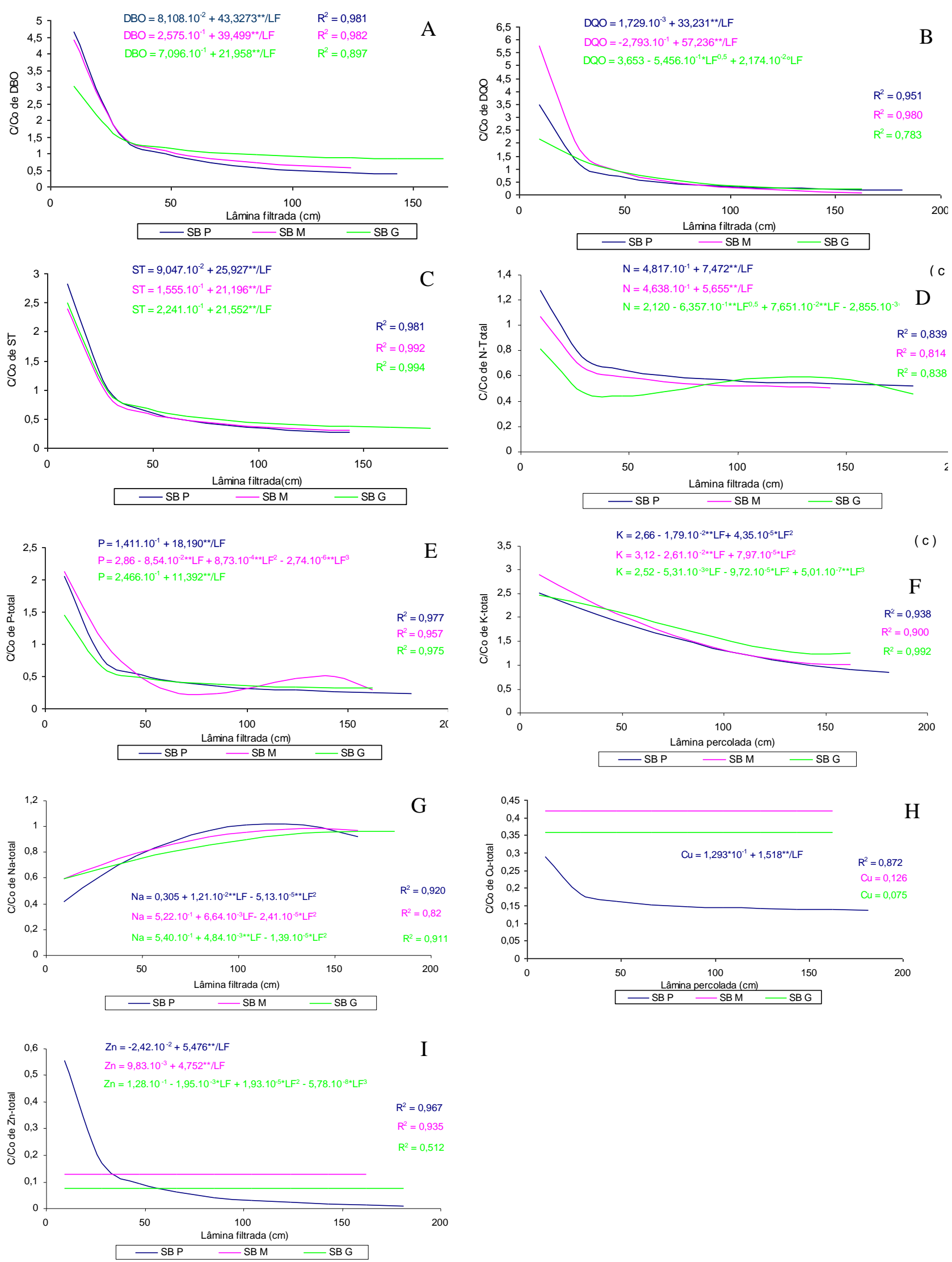

FIGURA 3. Concentração relativa estimada de (A) DBO, (B) DQO, (C) ST, (D) N-total, (E) P-total, (F) K, (G) Na, (H) Cu-total e (I) $\mathrm{Zn}$-total no efluente dos filtros que receberam água residuária da suinocultura em função da lâmina filtrada, em filtros compostos de triturado de sabugo de milho, em três faixas granulométricas: $\mathrm{P}$ - pequeno $(0,84 \mathrm{a} 1,19 \mathrm{~mm})$, M-médio $(1,19$ a 2,00 mm) e $\mathrm{G}$ - grande $(2,00$ a 2,83 mm). Estimated relative concentration of (A) BOD, (B) COD, (C) TS, (D) total-N, (E) total-P (F) K, (G) Na, (H) total-Cu and (I) total-Zn in the effluent of the filters receiving swine wastewater as a function of blade filtered in filters composed of corncob in three particle sizes: $\mathrm{S}$ - small $(0.84$ to $1.19 \mathrm{~mm})$, M-medium (1.19 to $2.00 \mathrm{~mm})$ and $\mathrm{G}$ - large $(2.00$ to $2.83 \mathrm{~mm})$. 
Nas primeiras lâminas filtradas, foram obtidas menores concentrações de DBO nos efluentes dos filtros de triturado de sabugo de milho com maior granulometria, tal como observado por LO MONACO et al. (2004a), utilizando serragem de madeira com as mesmas faixas granulométricas. Isso pode ter ocorrido em razão de as partículas de maior dimensão apresentarem menor superfície específica, diminuindo sua interação com o líquido percolante, o que diminui a possibilidade de solubilizar e transportar açúcares, carboidratos e outros materiais oxidáveis pelos micro-organismos.

De acordo com os dados apresentados nas Figuras 2-B e 3-B, a remoção de DQO não foi sensivelmente influenciada pela granulometria dos dois materiais filtrantes, tendo sido obtidas remoções de 50 a $80 \%$ no triturado de bagaço de cana e em torno de 50 a $60 \%$ no triturado de sabugo de milho, em todas as faixas granulométricas avaliadas. Da mesma forma como ocorrido com a DBO, os dois materiais filtrantes liberaram, nas primeiras lâminas filtradas, elevada quantidade de sólidos e solutos de fácil oxidação bioquímica e de magnitude muito superior à que foi reportada por LO MONACO et al. (2004a), quando utilizaram serragem de madeira.

Diferenças irrelevantes foram observadas na concentração relativa de sólidos totais (ST) nas três faixas granulométricas dos dois materiais filtrantes (Figuras 2-C e 3-C), principalmente a partir de $50 \mathrm{~cm}$ de lâmina de ARS filtrada. Ainda assim, proporcionaram eficiências na remoção de ST em torno de 55 e $60 \%$, para o triturado de bagaço de cana-de-açúcar picado e triturado de sabugo de milho triturado, respectivamente, a partir dos $100 \mathrm{~cm}$ de lâmina de ARS filtrada. Estes resultados foram superiores aos obtidos por BRANDÃO et al. (2000), LO MONACO et al. (2002), MAGALHÃES et al. (2005 e 2006b) e LO MONACO et al. (2009b) e inferiores aos obtidos por LO MONACO et al. (2004a), quando foram avaliados diferentes materiais como meio filtrantes de diversas águas residuárias. BRANDÃO et al. (2000), ao avaliarem diversos materiais filtrantes no tratamento da ARS, obtiveram baixa eficiência na remoção de ST, sendo a maior eficiência (33\%) obtida quando foi utilizado o fino de carvão vegetal. LO MONACO et al. (2002), trabalhando com serragem de madeira e triturado de bagaço de cana na faixa granulométrica de 2,83 a 4,00 mm, no tratamento da ARC, obtiveram remoções em torno de 65 e 40\%, respectivamente. MAGALHÃES et al. (2005 e 2006b), trabalhando com serragem de madeira e bagaço de cana-de-açúcar, no tratamento da ARS, obtiveram remoções de 43 a $57 \%$ e de 50 a $56 \%$, respectivamente. LO MONACO et al. (2009b), ao avaliarem a fibra de coco como material filtrante, no tratamento da ARS, obtiveram remoção média de ST de 46\%. LO MONACO et al. (2004a) obtiveram remoções em torno de 60 a $70 \%$ utilizando serragem de madeira, na mesma faixa granulométrica, no tratamento da ARS. Com base nos resultados obtidos e naqueles apresentados na literatura, verifica-se que materiais que solubilizam muitos sólidos são pouco eficientes na remoção de ST do que aqueles de caráter mais inerte, tendo em vista que contribuem com menor quantidade de sólidos solubilizáveis. Esse fato ficou evidente pela observação visual de aumento na coloração do efluente em relação ao afluente.

De acordo com os dados apresentados nas Figuras 2-D e 3-D, observa-se que não houve diferenças relevantes entre as faixas granulométricas na remoção de nitrogênio, nos dois materiais filtrantes avaliados, exceto nos primeiros $70 \mathrm{~mm}$ de lâmina de ARS filtrada, utilizando o sabugo de milho (Figura 3-D), no qual a maior faixa granulométrica pareceu ser mais eficiente. De maneira semelhante ao explicado em relação à DBO e DQO, isto pode ter ocorrido em razão de as partículas de maior dimensão do meio filtrante apresentarem menor superfície específica, diminuindo sua interação com o líquido percolante e, consequentemente, a possibilidade de solubilizar e transportar sólidos. De maneira contrária, LO MONACO et al. (2004a) obtiveram maiores remoções na menor faixa granulométrica, a partir dos $80 \mathrm{~cm}$ de lâmina filtrada de ARS.

Após estabilização na taxa de remoção de nitrogênio total da ARS efluente do filtro de triturado de sabugo de milho, verificou-se eficiência de aproximadamente $45 \%$ na remoção de $\mathrm{N}$-total (Figura 2-D). Ainda que não tenham sido analisadas as diferentes formas químicas do nitrogênio, acredita-se que a maior parte do $\mathrm{N}$ retido no material filtrante corresponde ao $\mathrm{N}$ -orgânico. As formas químicas minerais, principalmente a de $\mathrm{N}$-amoniacal, foram, possivelmente, 
retidas em menor proporção. No caso do bagaço de cana-de-açúcar, obteve-se eficiência média em torno de 50\% (Figura 3-D). Estes resultados foram semelhantes aos obtidos por diversos autores trabalhando com ARS, como LO MONACO et al. (2004a), que obtiveram remoções de 50\%, utilizando a serragem de madeira, e superiores aos obtidos por BRANDÃO et al. (2000), que encontraram pequena ou nenhuma alteração na concentração de $\mathrm{N}$-total no efluente do filtro, utilizando diversos materiais filtrantes, com granulometria entre 2 e $10 \mathrm{~mm}$, e por LO MONACO et al. (2009b), que obtiveram remoções médias em torno de 30\%, utilizando a fibra de coco, com granulometria entre 4 e $8 \mathrm{~mm}$. No entanto, foram inferiores aos obtidos por LO MONACO et al. (2002), que obtiveram remoções em torno de $80 \%$, quando utilizaram a serragem de madeira e o triturado de bagaço de cana-de-açúcar, com granulometria entre 2,8 e 4,00 mm, na filtragem de ARC.

Tal como observado em relação ao nitrogênio, não houve diferenças relevantes entre as faixas granulométricas na remoção de fósforo (Figuras 2-E e 3-E), nos dois materiais filtrantes avaliados, principalmente a partir dos $50 \mathrm{~cm}$ de lâmina de ARS filtrada, tendo sido obtidas remoções em torno de $65 \%$ em ambos os materiais. Se forem comparadas as curvas de remoção de sólidos totais (Figuras 2-C e 3-C) com as de fósforo total, verificam-se algumas semelhanças. Como o fósforo e o nitrogênio, ao contrário do que ocorre com o potássio e o sódio, apresentam forte associação com o material orgânico (LO MONACO et al., 2009), a retenção de material sólido, que ficou em torno de $60 \%$, de certa forma, pode também explicar os resultados de remoção alcançados em relação ao fósforo total. Dessa forma, quanto maior a remoção de sólidos totais da ARS afluente, maiores as remoções de P-total. Da mesma forma como discutido em relação ao nitrogênio, acredita-se que formas minerais de $\mathrm{P}$ (ortofosfatos ou polifosfatos) não tenham sido retidas de forma eficiente.

Os resultados obtidos neste trabalho foram semelhantes aos encontrados por LO MONACO et al. (2004a), que também obtiveram remoções de fósforo em torno de $65 \%$ e não observaram diferenças entre faixas granulométricas, na filtragem de ARS. Além disso, foram superiores aos encontrados por BRANDÃO et al. (2000), que observaram baixa ou nenhuma remoção de fósforo da ARS, quando utilizaram diversos materiais filtrantes, e LO MONACO et al. (2009b), que obtiveram remoção média de 58\%, trabalhando com fibra do coco no tratamento da ARS. Entretanto, foram inferiores aos obtidos por LO MONACO et al. (2002), que encontraram remoções em torno de $70 \%$, utilizando a serragem de madeira no tratamento da ARC.

Não houve remoção de potássio total pelos materiais filtrantes estudados, em nenhuma das granulometrias avaliadas (Figura 2-F e 3-F), sendo sua concentração, inclusive, maior que a obtida no afluente. Isso pode estar relacionado ao fato de o potássio não estar associado ao material orgânico (LO MONACO et al., 2009b) que, por sua vez, foi um material retido com eficiência em sua forma sólida. Conforme foi verificado em relação a ST, DBO, DQO e N-total, o bagaço de cana-de-açúcar e o sabugo de milho, ao invés de reterem potássio, liberaram-no, proporcionando a obtenção de efluentes ricos neste elemento químico. A solubilização do potássio presente nos materiais filtrantes, tal como já foi explicado em relação a outras variáveis avaliadas, pode ser a grande responsável pelas altas concentrações de potássio nos efluentes dos filtros que receberam ARS como afluente, comprovando o que diversos autores (BRANDÃO et al., 2000; LO MONACO et al., 2002; LO MONACO et al., 2004a; LO MONACO et al., 2004b; LO MONACO et al., 2009b) também observaram. Com o tempo de operação do filtro, o potássio extraível foi diminuindo no meio, razão por que os efluentes passaram a apresentar valores próximos ao de potássio presente na ARS afluente.

O sódio (Figuras 2-G e 3-G), de forma semelhante ao potássio, não foi significativamente removido por nenhum dos materiais utilizados como filtro, a não ser nos constituídos por triturado de bagaço de cana-de-açúcar, na menor faixa granulométrica do filtro, condição em que se obteve remoção média de $10 \%$. A pequena associação do sódio ao material orgânico que, em relação ao ST, foi retido com baixa eficiência nos filtros, pode ser a maior razão para os resultados obtidos e também observados por BRANDÃO et al. (2000), LO MONACO et al. (2002), LO MONACO et al. (2004a), LO MONACO et al. (2004b) e LO MONACO et al. (2009b). Como não houve remoção 
significativa de sódio da ARS afluente aos filtros, pouca discussão resta a respeito de possíveis efeitos do tipo e da granulometria do material.

O cobre (Figura 2-H e 3-H) foi eficientemente removido da ARS afluente nos filtros, tendo as eficiências de remoção ficado entre 85 e 95\%, após a estabilização do processo, nos filtros constituídos de triturado de bagaço de cana-de-açúcar (Figura 2-H). Nos filtros constituídos por triturado de sabugo de milho, as remoções estabilizaram-se entre 58 e $85 \%$, sendo as maiores remoções obtidas nos filtros constituídos com os materiais mais finos. Como o cobre está fortemente associado à matéria orgânica (LO MONACO et al., 2004a), torna-se razoável esperar que, quando houver maior concentração de sólidos totais e sedimentáveis no efluente, maior também deva ser a concentração de cobre. A influência da granulometria do material filtrante não ficou muito clara no caso da remoção de cobre, em vista da grande oscilação que ocorreu na concentração desse metal nos efluentes coletados; por essa razão, foram apresentadas somente as concentrações médias contidas nos efluentes dos filtros de cada faixa granulométrica. Entretanto, ficou evidente a superioridade das menores granulometrias nos dois materiais filtrantes, na remoção do cobre.

Todos os materiais, em todas as granulometrias, mostraram-se altamente eficientes na remoção de zinco da ARS afluente (Figuras 2-I e 3-I). Os resultados obtidos nos filtros constituídos por triturado de cana-de-açúcar ficaram um pouco comprometidos em virtude da grande oscilação observada na concentração efluente. Entretanto, pode-se verificar tendência de convergência das curvas para um valor único de taxa de remoção em torno de 94-96\%. Eficiências de remoção acima de $90 \%$ foram obtidas nos dois filtros, tendo sido obtidos valores de até $96 \%$ de remoção no filtro de triturado de bagaço de cana-de-açúcar, após a estabilização do sistema, alcançada após a aplicação de $50 \mathrm{~cm}$ de lâmina de ARS filtrada.

As altas eficiências obtidas neste experimento, na remoção de cobre e zinco da ARS, podem ser atribuídas a dois fatores principais: adsorção do metal em sítios de troca existentes na massa do material filtrante, conforme hipótese levantada por BRANDÃO et al. (2000), e retenção do material orgânico de maiores dimensões nos poros do material filtrante. $O$ zinco, estando quelado/complexado pelo material orgânico que ficou retido nos poros do material filtrante, foi, dessa forma, removido do líquido em percolação.

As maiores concentrações de zinco encontradas nos efluentes de todos os filtros, relativos às primeiras lâminas, podem, tal como foi verificado em relação a outros elementos químicos, ser atribuídas à solubilização do material filtrante e ao seu posterior transporte com o líquido percolante.

Não foi encontrada influência da granulometria do triturado de sabugo de milho na remoção de zinco da ARS afluente, após a estabilização do sistema. Verificou-se, porém, que nos filtros contendo materiais com menores faixas granulométricas, a estabilização nas taxas de remoção foi obtida mais rapidamente que quando foram utilizadas faixas médias e grandes.

\section{CONCLUSÕES}

No início da operação dos filtros, em geral, menores concentrações de DBO nos efluentes foram obtidas naqueles de maior granulometria.

A remoção de DQO, ST, N-total e P-total não foi sensivelmente influenciada pela granulometria nos dois materiais filtrantes avaliados.

O potássio e o sódio não foram retidos nos materiais filtrantes, em nenhuma das faixas granulométricas estudadas; entretanto, as maiores remoções de metais pesados $(\mathrm{Cu}$ e $\mathrm{Zn})$ foram obtidas, no geral, nos filtros de menor faixa granulométrica.

Verificou-se que o tipo de material filtrante pode influenciar na qualidade do efluente, notadamente no seu início de operação, devendo ser escolhido de forma a proporcionar a geração de um efluente cujas características estejam mais próximas das desejadas. 


\section{REFERÊNCIAS}

APHA. AMERICAN PUBLIC HEALTH ASSOCIATION. Standard methods for the examination of water and wastewater. $21^{\text {th }}$ ed. Washington: APHA, $1.600 \mathrm{p}$.

BATISTA, R.O.; MATOS, A.T.; CUNHA, F.F.; LO MONACO, P.A. Formação de biofilme em gotejadores aplicando água residuária da despolpa dos frutos do cafeeiro. Acta Science Agronomy, Maringá, v.29, n.3, p.367-371, 2007.

BATISTA, R.O.; MATOS, A.T.; CUNHA, F.F.; LO MONACO, P.A. Obstrução de gotejadores utilizados para a aplicação de água residuária da despolpa dos frutos do cafeeiro. Revista Irriga, Botucatu, v.10, n.3, p.288-294, 2005.

BRANDÃO, V.S.; MATOS, A.T.; FONTES, M.P.F.; MARTINEZ, M.A. Retenção de poluentes em filtros orgânicos operando com águas residuárias da suinocultura. Revista Brasileira de Engenharia Agrícola e Ambiental, Campina Grande, v.7, n.2, p.329-334, 2003.

BRANDÃO, V.S.; MATOS, A.T.; MARTINEZ, M.A.; FONTES, M.P.P. Tratamento de águas residuárias de suinocultura utilizando-se de filtros orgânicos. Revista Brasileira de Engenharia Agrícola e Ambiental, Campina Grande, v.4, n.3, p.327-333, 2000.

DAL BOSCO, T.C.; SAMPAIO, S.C.; OPAZO, M.A.U.; GOMES, S.D.; NÓBREGA, L.H.P. Aplicação de água residuária de suinocultura em solo cultivado com soja, cobre e zinco no material escoado e no solo. Revista Engenharia Agrícola, Jaboticabal, v.28, n.4, p.699-709, 2008.

FREITAS, W.S. Desempenho de sistemas alagados construídos, cultivados com diferentes espécies vegetais, no tratamento de águas residuárias da suinocultura. 2006. 159 f. Tese (Doutorado em Engenharia Agrícola) - Universidade Federal de Viçosa, Viçosa, 2006.

LO MONACO, P.A.; MATOS, A.T.; GARCIA, G.O.; LIMA, C.R.C.; FAZENARO, F.L. Avaliação do pergaminho dos frutos do cafeeiro como elemento filtrante no tratamento de águas residuárias da lavagem e despolpa dos frutos do cafeeiro. In: CONGRESSO NACIONAL DE IRRIGAÇÃO E DRENAGEM, 14., 2004, Porto Alegre. Anais... Porto Alegre-RS: 2004b. 1 CD-ROM.

LO MONACO, P.A.; MATOS, A.T.; JORDÃO, C.P.;CECON, P.C.; MARTINEZ, M.A. Influência da granulometria da serragem de madeira como material filtrante no tratamento de águas residuárias. Revista Brasileira de Engenharia Agrícola e Ambiental, Campina Grande, v.8, n.1, p.116-119, 2004a.

LO MONACO, P.A.V.; MATOS, A.T.; MARTINEZ, H.E.P.; FERREIRA, P.A.; RAMOS, M.M. Características químicas do solo após a fertirrigação do cafeeiro com águas residuárias da lavagem e descascamento de seus frutos. Revista Irriga, Botucatu, v.14, n.3, p.348-364, 2009a.

LO MONACO, P.; MATOS, A.T.; MARTINEZ, H.P.; FERREIRA, P.A.; RAMOS, M.M. Avaliação do estado nutricional do cafeeiro após a fertirrigação com águas residuárias da lavagem e descascamento de seus frutos. Revista Engenharia na Agricultura, Viçosa-MG, v.15, n.4, p.392399, 2007.

LO MONACO, P.A.; MATOS, A.T.; MARTINEZ, M.A.; JORDÃO, C.P. Eficiência de materiais filtrantes no tratamento de águas residuárias da lavagem e despolpa dos frutos do cafeeiro. Revista Engenharia na Agricultura, Viçosa-MG, v.10, n.1-4, p.40-47, 2002.

LO MONACO, P.A.V.; MATOS, A.T.; SARMENTO, A.P.; LOPES JÚNIOR, A.V.; LIMA, J.T. Desempenho de filtros constituídos por fibras de coco no tratamento de águas residuárias de suinocultura. Revista Engenharia na Agricultura, Viçosa-MG, v.17 n.6, p.473-480, 2009b.

MAGALHÃES, M.A.; MATOS, A.T.; DENÍCULI, W.; AZEVEDO, R.F. Influência da compressão no desempenho de filtros orgânicos para tratamento de águas residuárias da suinocultura. Revista Engenharia na Agricultura, Viçosa-MG, v.13, n.1, p.26-32, 2005. 
MAGALHÃES, M.A.; MATOS, A.T.; DENÍCULI, W.; TINOCO, I.F.F. Compostagem de bagaço de cana-de-açúcar triturado utilizado como material filtrante de águas residuárias da suinocultura. Revista Brasileira de Engenharia Agrícola e Ambiental, Campina Grande, v.10, n.2, p.466-471, 2006a.

MAGALHÃES, M.A.; MATOS, A.T.; DENÍCULI, W.; TINOCO, I.FF. Operação de filtros orgânicos utilizados no tratamento de águas residuárias da suinocultura. Revista Brasileira de Engenharia Agrícola e Ambiental, Campina Grande, v.10, n.2, p.472-478, $2006 \mathrm{~b}$.

MATOS, A.T. Tratamento de resíduos na pós-colheita do café. In: BORÉM, F.M. (Ed.). Pós-colheita do café. Lavras: Ed. UFLA, 2008. cap. 6, p.159-202.

MATOS, A.T.; MAGALHÃES, M.A.; FUKUNAGA, D.C. Remoção de sólidos em suspensão na água residuária da despolpa de frutos do cafeeiro em filtros constituídos por pergaminho de grãos de café submetido a compressões. Engenharia Agrícola, Jaboticabal, v.26, n.2, p.610-616, 2006. 